\title{
Exploration and Analysis of Ways to Improve Hidden Psychological Harm in Dormitories of College Students from the Perspective of Team Sand Play Games
}

\author{
Zhang Yi \\ Shaanxi University of Science and Technology Mental Health Center \\ Department of Engineering, Shaanxi University of Science and Technology \\ Weiyang District, Xi'an City, Shaanxi Province, 710021
}

\begin{abstract}
Nowadays College students' psychological problems tend to be complex and diverse, especially hidden psychological harm. Due to its prominent characteristics, such as high incidence, strong concealment and strong lag, it has significant impact and harm. On the basis of the existing mature dominant psychological education, group sand play games play a hidden role in the psychological health education of college students and prevent students from hiding psychological harm. Meanwhile, the games expand psychological health education system for college students and provide a theoretical basis for further study.
\end{abstract}

Keywords-Team Sand Play Games; Hidden Psychological Injury; Dormitory Interpersonal Relations

\section{THE THEORETICAL BASIS OF TEAM SAND PLAY GAMES}

\section{A. The defination of team sand play games}

This therapy was firstly created and developed by D.M.Kaoff in the 1980s. The sandplay game is psychological counseling behavior which is out of the team environment to carry out a series of sand paly games. The game is the most important medium, and many visitors choose their own toys and then create their works in sand table in the company of consulting stuff. In the process, visitors promote individual awareness and explore themselves, observe and accept others through the group interpersonal communication. They also acquire new attitudes and behavior patterns and thus form a good and adaptive process to help others [1].

\section{B. The process of team sand play games}

The game is that team members set up works in the same sandbox, and the members must follow the rules: first, the complete game is at least five rounds each time, and team members in each round only have one chance. They must place toys in order by means of a predetermined way such as Rockpaper-scissors game and draw size and so on; second, members cannot communicate with each other in words or bodies while placing [2].

\section{The advantages of team sand play games}

First, in recent years, this therapy has become a commonly used method in relative research and practice due to its advantages such as economy payment, time saving, effectiveness and furthest utilization of group power fields; second, the relevant studies have shown that this therapy understands the patterns of interpersonal activity through various verbal and non-verbal acts. It can make adjustments of relationship and emotion in group counseling, and then enhance cohesion, push members to communicate and understanding well; third, the game can promote the psychological growth of players, and effectively use their own healing abilities and enhance the group driver.

\section{RESEARCH OF COLLEGE STUDENTS HIDDEN INTERPERSONAL PSYCHOLOGICAL HARM}

\section{A. The definition and characteristics of college students hidden psychological harm}

Compared with common dominant injury events, conscious or unconscious activities in study, work and life lead to hidden injuries in physical and psychological aspects and interpersonal relationships among college students. In most cases, the involved are not aware of prominent abnormalities at the beginning, and ultimately the extreme adverse impact will get attention in public. Interpersonal tension causes difficult communication, introverted students cannot get enough respect and understanding of others and then lead to psychological problems, which are all hidden injuries. The hidden psychological injury of college students often has the characteristics of being unintentional, diffusing, destructive, disruptive, delaying and concealed, which make the harmful behavior easily repeated, which have an immeasurable impact on the mental health of college students and finally changes to great explicit damage. According to the origins of adolescent hidden injuries, they are mainly divided into teacher-based hidden injuries, student-based hidden injuries and school-based hidden injuries. It is obvious that the hidden psychological injury in dormitories belongs to student-based hidden injury. 


\section{B. The performance of the hidden psychological harm in dormitories}

\section{1) Anxiety caused by learning atmosphere}

Poor learning atmosphere will seriously affect other members of the dormitory, and individual students who have negative attitude toward learning and lose learning motivation will change the overall learning atmosphere of the dormitory bad. Meanwhile, the individual students are vulnerable to affect by learning environment. Especially for boys, it is common to see that they love online games and fail exams. Therefore, the dormitory staffs are prone to academic stress, test anxiety. Some students with poor grades are more likely to join highrisk groups of psychological problems.

\section{2) Interpersonal conflicts caused by dormitory daily affairs} Manifested in two aspects:

(1)Problems in shift of dormitory health day and watercarrying: some dormitory members are not self-conscious. Holding the value of the daily table, they often forget the value date, and it is useless to remind them. If they are not reminded, if you do not remind, the chief will shoulder the tasks. Some hostels also observe the value date table at the beginning, but some roommates gradually fail to obey the rules, and they just clean up before checking and often do not pay attention to maintaining collective health in the dormitory. Verbal disputes arising from the rotation of cleaning, the backlog of negative emotions in the minds for a long time are all the causes of the conflict in dormitory;

(2)Problems in dormitory work and rest: at night some students turn off the lights too late, or open the vowel to watch the video, which affects other roommates to rest. If it is the test week, some students will stay up all night to review or study, resulting in contradictions and disputes in hostels. It is also the main reason for the discordant atmosphere of the hostel

3) Inappropriate communication among dormitory members affects the development of personality

If the dormitory members communicate less, it is easy for members to stay alone in the dormitory or reject dormitory activities. The dormitory relationship is not close or harmonious;

The dormitory members also have the phenomenon of "gang-pulling". Students who encounter problems may not get sufficient social support from their roommates and classmates. Inner conflicts caused by poor communication among dormitory members may easily lead to hidden psychological problems. Senior students generally reflect that they are busy with learning, and they are under pressure. So they ignore their roommates.

These factors are easy to affect the centripetal force among the dormitory members. Dormitory harmonious relationship is crucial to the development of personality in college students' stage.

\section{Analysis of Reasons of Hidden Psychological Harm of College Students in Dormitory}

The harmony of college dormitory is affected by many factors, and the factors of individual and dormitory environment are the main causes of the hidden psychological injury of interpersonal relationship in college dormitory.

\section{1) Iisolated from their companion}

In the campus survey, it shows that college students were most afraid of being isolated from their dorm roommates, and over half of them said they were "isolated." Isolated students are generally divided into three categories: first, students with a flawed personality in some aspect, such as being introverted, withdrawn and communicate with others less; second, students with difficult economic conditions and common appearance and

poor academic performance of students; third, students who are particularly good at learning with good family conditions and outstanding, liked by their teachers easily get other students' jealousy, rivalry and hostility because of being too strong or misbehaving in language actions. Isolated students will feel abandoned, denied, depressing in the dormitory, affecting normal interpersonal skills, exacerbating or exacerbating the feeling of loneliness, refusing to cooperate or rejected by others.

\section{2) Improper speech among classmates}

Speech harm is the most direct and simple way to hurt. It is called "language violence" in psychology. That results in people's mental and psychological aspects which have been violated by using abusive, contempt, ridicule and other offensive words, and that is typical mental injury. It is very easily to form "retarded personality" (That is evading the problems and the status quo, and people cannot effectively communicate with others, and they are prone to being introverted, autistic and suspicious) and "aggressive personality" (After suffering from "verbal violence", the character becomes extreme, irritable, resentful, and they will commit aggressive behavior to others and even society).

\section{3) Discriminated by students}

The main types of being discriminated are: competency discrimination, appearance discrimination, geographical discrimination and implicit discrimination. Being looked down upon is the most fearful in the growth of students in interviews, and the feeling comes from their own personal image, academic performance, family background and attitudes of people around them. Students who are discriminated feel inferiority, be hurt in self-esteem. Introverted students will suffer depressive disorder for a long time, and extroverted students will behave extremely, and their behaviors endanger the society, and they will vent their dissatisfaction with offensive and cruelty behaviors. 


\section{4) Crowd effect in dormitory}

The dormitory actually is a kind of group psychology and value system formed by all its members. With the joint action of all the members and the dormitory and the help of the group dynamics such as emotion infiltration, imitation and conformity, all members of the dormitory build up a unified psychological, emotional and behavioral approach. The past theoretical results show that dormitory members through the depth of communication, frequency of activities, frequency of contradictions, frequency of mood sharing and frequency of participation in collective activities, etc. will have a tremendous impact on the harmonious quarters. Each member of the dormitory can feel the psychological power of the group, and then show the huge psychological effect of the dormitory group. Therefore, we must understand how to make use of the hidden effect of such group psychological effects so that all dormitory members can acquire full understanding and support and build a good psychological compatibility, and then change the above positive emotions with the psychological effects of such groups to show their own utility, to promote the building of a harmonious dormitory of the inner power.

\section{STUDY ON WAYS TO IMPROVE HIDDEN PSYCHOLOGICAL HARM IN DORMITORY OF COLLEGE STUDENTS BY GROUP SAND PLAY GAMES}

\section{A. Team sand play games can effectively reduce anxiety}

When the roommates are in the hidden psychological problems, their feeling of powerlessness will cause this group under agitated conditions permanently and cannot deal with them effectively. The research shows that the more social support individuals receive and lower their anxiety levels are. Individuals under anxiety conditions will be accustomed to using various types of defensive measures [3]. Relevant analysis shows that the anxiety groups have characteristics of being introverted and unstable. In general, imaginary or defensive measures are taken in attempts to evade contradictions. With the help of sand table, the usual inconvenience is expressed. In the process of group sand play games, the therapists should express enough acceptance and concern for the roommates, so that they can continuously improve their sense of efficacy in the atmosphere of empathy and mutual respect and support among their roommates to ease the anxiety. Sand play game is an unconscious description of the individual by passing the impedance, venting their psychological negative emotions and energy accumulated daily, escaping their psychological anxiety, panic and other negative emotions, accompanied by consciousness or unconscious relationship coordinated development, and ultimately to rebuild and strengthen themselves.

\section{B. Team sand play games can provide a good platform for friendly communication in dormitories}

In the games, the members are not allowed to communicate with each other in the process of building sand table without subject restrictions, and after the end all the members explain the meaning for the concept of their own construction and the meaning of the toys position, and then name the whole work together. In the free, fair, lively and safe environment built by the consultants, individuals build the sand table to complete the process of self-exploration from the soul to the material and from the non-language to the language through the team. The sharing and naming stage enhances mutual understanding to solve a lot of misunderstandings and estrangements caused by lack of communication, and finally achieve $\mathrm{Wu}$ Wei. In the building process, collective communication should be carried out after each construction of the sand table. At the beginning, all members focus on explaining their inner feelings, and seldom depict feelings about others, and rarely think about the team. With this construction being done again and again, the members increasingly communicate with others. All members do not only discuss their own feelings, but also express their own problems and expectations of the whole work. With these effective discussions, members have come to realize that many problems are actually rooted in cognitive bias, and erroneous conclusions appear due to erroneous understanding of each other's intentions.

\section{Group sand play games can inspire self-Consciousness}

The active participation of dormitory members is actually one of the major factors that have a huge impact on the harmonious dormitory of colleges. It is also the main source of hidden psychological injury in dormitory. Interpersonal relationships inside the group sand table construction and real life have oneness which is the cooperation process. During the Sand table construction, it will maximize the realization of the dormitory run-in and integration with full participation and integration. In turn, if the dormitory members can not effectively integrate with other members or even encourage themselves, and the sand play game can help to find personal negative coping and defense and indifferent attitude to the other members of the dormitory. Through the inspection of the sand table in question, the hidden psychological injury among the groups is enormous. At the beginning the most notable feature of the group is that the group is like a mess of sand and builds it alone. Everyone wants to make every effort to demonstrate his own ideas, seldom considering the collaboration with others while choosing and placing toys. As a result, the toys are constantly moved by each other, and the groups show the tendency of confrontation, and the sand table is out-of-order. When naming the works, all members feel that it is extremely difficult and the names are varied and different. Backing to the real life, the roommates do have the exclusion or resistance. However, after the much practice, the group will enter the period of integration and regression. The theme of the work will be more and more unified. Self-awareness will be enhanced, and group motivation will enhance psychological integration and eventually promote self-growth and perfect personality. 
D. Group sand play games can cultivate college students to establish good social relations

The most important social relationship among college students is family relationship and social interpersonal relationship. In the process of sand game, it is easy to touch the trauma caused by the original family in childhood through consciousness and unconsciousness. This enables them to balance external and internal realities and gradually achieve the purpose of correcting behavior and self-healing. In addition to family relationships, interpersonal relationships are also an important part of college students' social relations. College students should actively cultivate the psychological quality of trust, forgiveness and gratitude [4]. Through the game rules set up by the group sand table, they should promote the interpersonal interaction between groups and promote the individual self whose purpose is to develop a good self-help function, group sandtable games can also promote the psychological development and growth of individual members, bring into play the group dynamic field formed by the combination of individual self-healing power, and learn to feel, observe and accept others, establish correct cognition and behavior way reasonably in the process, and then cultivate college students can establish good social relationship and positive psychological quality in the sharing stage of learning group members.

\section{CONCLUSION}

Sand table play therapy is beneficial to the cultivation of positive psychological quality of college students and plays an important role in fostering excellent and good qualities of college students. The recessive psychological injury of college students' dormitory can be improved by group sand table games. Help college students to improve their positive personality, guide them to form positive emotions, cultivate college students to establish good social relations, so as to effectively enhance the ability of college students to resist setbacks and improve the ability of college students to deal with problems. Help college students better adapt to the increasingly competitive society, better achieve success, and obtain enough happiness.

\section{REFERENCES}

[1] Barbara Labovitz Boik. (2014). SandplayTherapy - Psychotherapy Practitioners Manual. (Tian Weibao Translated). China Light Industry Press.

[2] Kalff, D. M. (2003). Sandplay: A Psychotheraputic Approch to the Psyche. Santa Monica: Sigo Press.

[3] Qi Chengyong. On the Implicit Efficacy and Release Paths of College Students' Positive Mental Health Education [J]. Journal of Hunan University of Science and Technology, 2012 (7): 6-17.

[4] Wang Lanfeng. Students Hidden Psychological Injury and Avoidance Strategies [J]. Journal of Inner Mongolia Normal University (Education Science Edition), 2014 (8): 47-49.University Science, 1989. 